\title{
Representaciones del bien y del mal en la Castilla del siglo XIII
}

\author{
Carina Zubillaga \\ carinazubillaga@hotmail.com \\ Seminario de Edición y Crítica Textual. Instituto \\ de Investigaciones Bibliográficas y Crítica Textual. \\ Universidad de Buenos Aires / CONICET, Argentina
}

Recepción: 30 Octubre 2020

Aprobación: 24 Abril 2021

Publicación: 03 Mayo 2021

Cita sugerida: Zubillaga, C. (2021). Representaciones del bien

y del mal en la Castilla del siglo XIII. Olivar, 21(33), e092.

https://doi.org/10.24215/18524478e092

La promoción del castellano como lengua literaria en la primera mitad el siglo XIII, a través de la literatura clerical generalmente identificada con el "mester de clerecía" como escuela poética, supone una ejemplaridad asentada en una ética cristiana en la que la oposición bien-mal resulta determinante. Los poemas escritos en el metro estilizado de la cuaderna vía, como los Mlagros de Nuestra Señora de Gonzalo de Berceo y el Libro de Apolonio, así como otros compuestos en pareados irregulares populares como la Vida de Santa María Egipciaca y el Libro de los tres reyes de Oriente, responden a impulsos clericales cuya premisa esencial es la traducción y adaptación de tradiciones latinas previas y otras europeas más cercanas al contexto castellano. En textos en prosa sobre todo de la segunda mitad del siglo XIII o incluso principios del siglo XIV, asimismo, como Sendebar, La fazienda de Ultramar, la Gran conquista de Ultramar y la Historia troyana polimétrica, siguen identificándose prácticas discursivas y procedimientos tendientes a promover el castellano como lengua literaria a través de la traducción de motivos, historias y lenguas 
diversas, adaptando esas tradiciones a un discurso ejemplar configurado básicamente por las representaciones del bien y del mal, a pesar de sus disímiles textos fuente y de sus adscripciones genéricas diferentes.

El hibridismo cultural resultante de gran parte de la producción letrada del siglo XIII en Castilla, así como las estrategias de reformulación y asimilación que esos textos atraviesan para adaptarse al contexto castellano, se profundiza en este dossier a partir de una serie de artículos atentos al sistema cultural que privilegia esta literatura en su carácter ejemplar y que encuentra una de sus principales manifestaciones en la oposición de las fuerzas del bien y del mal. El volumen, dedicado a las representaciones del bien y del mal en la Castilla del siglo XIII y comienzos del siglo XIV, reúne los estudios de jóvenes investigadoras que han desarrollado su trabajo en el marco de tesis doctorales recientemente defendidas, a punto de presentarse y en proceso de desarrollo, y de su directora, y resulta un aporte a la temática fruto, en este sentido, tanto de esfuerzos y preocupaciones individuales como de diálogos críticos e intereses compartidos.

En todas las contribuciones del dossier, las representaciones del bien y del mal son analizadas en su doble articulación con el discurso ejemplar de la producción de los siglos XIII e inicios del XIV y con los discursos relacionados con los peligros que acechan a la vida humana en comunidad y los medios de contención y mantención de un orden político-social esencial en este periodo. Este abordaje, que supone lo contextual en sus diferentes manifestaciones, tiene en cuenta asimismo que, al ser básicamente adaptaciones o reformulaciones de tradiciones previas, esas representaciones asumen en los relatos diversas estrategias de asimilación para adaptarse al contexto castellano bajomedieval.

El trabajo inicial de María Eugenia Alcatena "El banquete macabro: la risa antropofágica en la Gran Conquista de Ultramar" se concentra en una temática asociada al mal, la de la antropofagia en esta extensa crónica castellana de fines del siglo XIII sobre los hechos concernientes a las cruzadas, para indagar en su relación con los padecimientos, percances y peligros que debe afrontar el ejército cristiano. El análisis del episodio, que proviene de la tradición de relatos sobre las cruzadas, conduce a la autora a subrayar los rasgos distintivos de su reelaboración en la crónica; entre esos rasgos, la pulsión antropofágica del grupo específico de los tahúres dentro del ejército cristiano permite reconsiderar la temática a través de las asociaciones humorísticas del episodio. Su condición marginal con respecto a la totalidad del ejército cristiano, además, posibilita profundizar en nociones relativas a la jerarquía, la disciplina como respuesta al caos y la medida del orden, a través de lo macabro y sus efectos.

En "El cuerpo de los pecadores en los Milagros de Nuestra Señora de Gonzalo de Berceo", Jezabel Koch analiza cómo la oposición bien-mal se desarrolla en la poética berceana a partir de los cuerpos de los pecadores, tensionados por las fuerzas opuestas que los disputan. Considera en principio el cuerpo en su relación con el mal, a través de la figura diabólica por antonomasia; posteriormente el bien, encarnado en la Virgen María que intercede y salvaguarda la integridad física de los pecadores; y, finalmente, el cuerpo mismo de los pecadores como el espacio en el que se inscribe el milagro. La salvación tanto del alma como del cuerpo ocupa, según las apreciaciones de la autora, un lugar relevante en los Milagros de Nuestra Señora como texto paradigmático de la clerecía castellana.

Melisa Marti, en "Discusiones doctrinales y problemas de traducción: la representación de la Santísima Trinidad, la Virgen María y los ángeles en La fazienda de Ultramar", se centra en el estudio del castellano como vehículo de las palabras sagradas, enfocando específicamente La fazienda de Ultramar como un texto que traduce la Biblia a la manera de los itinerarios o guías de peregrinos medievales. La temática de la traducción medieval en tanto adaptación no solo textual, sino esencialmente contextual, le permite acercarse a las modificaciones, supresiones, amplificaciones, reordenamientos, superposiciones, entre otros procedimientos que tienen a la geografía santa como eje fundamental. A través del análisis de las operaciones discursivas de La fazienda en relación con sus fuentes y otros romanceamientos del periodo, la autora aborda el estudio de la representación de la Santísima Trinidad, la Virgen María y los ángeles para profundizar en el sistema cultural y el modo de trabajo del traductor-autor. La atención especial a aquellos pasajes que muestran una desviación con respecto al canon bíblico, además de considerar la multiplicidad de las fuentes textuales 
de La fazienda, la incorporación de relatos apócrifos, citas litúrgicas, microrrelatos históricos y mitológicos, posibilita reconstruir el panorama de los debates filosófico-doctrinales del siglo XIII acerca del bien y del mal en su marco histórico-cultural.

El trabajo de Agustina Miguens, “'Mollis o fortis femina?: la ambigüedad del personaje de Briseida en la Historia Troyana Polimétrica", aborda la temática amorosa y, particularmente la figura de Briseida, en la Historia Troyana Polimétrica de fines del siglo XIII, o principios del siglo XIV según los estudiosos más recientes de la historia. A través del análisis del desarrollo de la figura femenina y su consideración a partir del enamoramiento doble de Troylo y Diomedes -no simultáneo, sino sucesivo-, indaga en el cambio en sus afectos como eje de la inconstancia femenina de acuerdo con la apreciación medieval. Los códigos del amor cortés, que permiten un retrato positivo de Briseida, se superponen textualmente con el discurso misógino medieval que reprocha su comportamiento; de este modo, el tópico de la mollis femina, la mujer de voluntad variable, se opone a la fuerte y constante fortis femina posiblemente en referencia a la Virgen María como modelo virtuoso. El pecado de la lujuria, que en el texto alcanza a la figura de Elena además de la de Briseida -tomando connotaciones políticas relacionadas con la caída de Troya- se contrapone, en este sentido, a la virtud femenina cuyo epítome es la Virgen María como esposa y madre santa. Sin embargo, no deja de percibirse en el relato narrativo una consideración positiva del amor y de Briseida como amante, diferente de lo que sucede con adaptaciones subsiguientes centradas en la inconstancia natural de las mujeres, como las de Boccaccio o Shakespeare.

En "La representación de contextos urbanos en Sendebar: la ciudad y sus peligros", Florencia Miranda analiza esta colección de relatos ejemplares traducida del árabe al castellano por mandato del infante Fadrique, hermano menor del rey Alfonso X en 1253, lo que lo convierte en uno de los primeros testimonios de prosa ficcional en castellano. En la cotidianeidad de ciertos ambientes y espacios presentes en los apólogos, más allá del ambiente cortesano del relato marco, la autora subraya un vínculo entre la cotidianeidad urbana plasmada en las historias y situaciones de criminalidad y peligrosidad que se entroncan con el discurso ejemplar de la colección, que puede ser considerada como un espejo de príncipes. Los peligros y las potenciales situaciones desagradables que implica la vida en la ciudad incluyen los engaños de las mujeres, como parte de la descalificación de la figura femenina de la colección, pero los exceden para centralizar las motivaciones y justificaciones asociadas con el rédito económico dentro de todo lo que es considerado negativo en la cosmovisión de la literatura ejemplar.

Finalmente, en "El bien plural frente al mal singular en los relatos del Ms. Esc. K-III-4 (Libro de Apolonio, Vida de Santa María Egipciaca, Libro de los tres reyes de Oriente)", Carina Zubillaga indaga en la dinámica compositiva de los tres poemas que integran el manuscrito K-III-4 de la Biblioteca de San Lorenzo de El Escorial (Libro de Apolonio, Vida de Santa María Egipciaca, Libro de los tres reyes de Oriente), los cuales comparten muchos rasgos temáticos y estructurales a pesar de sus diferencias métrico-estróficas y genéricas. Entre sus similitudes más destacadas, está la oposición como dinámica constitutiva de cada una de las historias, en especial mediante la contraposición del bien y el mal que se reitera en personajes y situaciones de estos poemas de la primera mitad del siglo XIII y de clara orientación clerical. De acuerdo con ese ámbito clerical de producción y circulación de estas historias, el mal se identifica con la individualidad en tanto el bien asume un carácter plural que remite, en definitiva, a la idea de la familia cristiana como ideal social propuesto. La identificación religiosa del mal con el pecado se destaca en especial en cada uno de los poemas a través de la relación del pecado paradigmático de la lujuria y la figura femenina; deudora de una visión clerical de la mujer como proclive al pecado, ya el Libro de Apolonio se inicia con el tema del incesto y la identificación de la hija de Antíoco con el pecado, muriendo ella misma con el mismo castigo divino que el de su padre, a pesar de ser su víctima. La Vida de Santa María Egipciaca lleva esta asociación al lugar central del relato de la vida de esta prostituta que luego se convertirá en santa por su penitencia por ese pecado, en tanto el Libro de los tres reyes de Oriente se aparta del pecado para centrarse directamente en la figura mariana como figura materna y, así, subordinar la identidad femenina a esa función integradora de lo femenino al orden familiar y social. 
De esta manera, el monográfico recorre un amplio espectro de la literatura ejemplar medieval castellana del siglo XIII, relevando aquellos fenómenos que suelen privilegiarse como manifestaciones del mal (en particular el antifeminismo y las representaciones demoníacas), a los que se opone el bien como clave del mensaje moral y didáctico de las historias. En tanto representaciones tempranas del bien y del mal en estos textos ejemplares, las consideramos relevantes para apreciar las dinámicas de la literatura castellana en su periodo de emergencia; esperamos que así pueda apreciarse en las páginas siguientes. 